Sofrimento psíquico à margem do SUS: vastidão e confinamento da clínica

Teresa Cristina Endo

São Paulo: Zagodoni, 2017, 140 págs.

\title{
Psychic Geographies
}

\section{Geografias psíquicas}

Iza Maria de Oliveira*1

É inverno em terras sulinas, ainda não geou. A estética do frio, de Vitor Ramil, aquece. Cá estou, na sala de atendimento de uma instituição pública de saúde mental (CAPS II Colmeia, Ijuí, RS), onde iniciaremos mais um encontro de uma atividade clínica que se chama "Palabrincar", cujo propósito é trabalhar clinicamente, através do lúdico, com pacientes em sofrimento psíquico. Palavras para brincar. A obra Sofrimento psíquico à margem do SUS, de Teresa Endo, encontra-se em cima de minha mesa. Havia recebido na caixa do correio no dia anterior, quando os termômetros marcavam seis graus. Pegar aquele envelope, rasgar com a força das almas insanas, percorrer com os dedos gélidos a beleza da diagramação e a textura aveludada daquela obra, era o aquecimento esperado para o dedo polegar não congelar. Na sala do CAPS, ainda não aquecida, a

${ }^{* 1}$ Psicanalista, cronista (Ijuí, RS. Br). 


\section{RESENHAS BIBLIOGRÁFICAS}

mulher loira, meia-idade, vocifera: "Que interessante o nome desse livro!". Imediatamente, ofereço-lhe um saboroso chimarrão, claro que curiosa para saber o que ia compor e se desenrolar a partir daquele momento. Ela fica por longo tempo folheando as páginas, provavelmente lendo algumas passagens, enquanto o restante das pessoas se ocupava com o jogo das Cinco Marias. Observo-a meio atordoada com a cena completamente inesperada. Primeiro porque sempre há algum livro em cima de minha mesa, e nunca nenhum paciente nos 17 anos que cá estou, havia feito algum gesto próximo daquele. Por que justamente essa obra? Seria por que aquela mulher se reconheceu na palavra "margem"? Após um tempo, ela me devolve. Meu corpo fica paralisado como num susto que nos retira da cena. Quero reagir, perguntar algo. Nada. Estado de comoção tal como a menina em Felicidade clandestina quando, finalmente, conseguiu o empréstimo do livro de Monteiro Lobato, no conto de Clarice Lispector. "Muito interessante esse livro", a mulher loira pronuncia devolvendo aquela obra de Teresa Endo. Então, alguém vocifera em mim: "Se quiser emprestado após eu ler, posso fazer isso". Ela sorri como se encontrasse, nesse momento, alguém junto que não a deixasse sucumbir às suas margens. Era um momento de Felicidade nada Clandestina. Para ela. Para mim.

Sofrimento psíquico às margens do SUS é uma das obras máximas no campo da clínica na saúde mental. Sim. A contundência em concebê-la assim, já de início, se justifica pela literatura existente nesse campo. Justifica-se pela força da clínica que transpassa cada palavra, cada pontuação, cada conjugação verbal, cada concordância pronominal; cada novo parágrafo até o último suspiro da obra, clinicamente posicionada.

Vale a pena algumas linhas sobre esse termo tão palavreado: "clínica". A autora exala clínica no seu texto. Não, exclusivamente, por se tratar de uma psicanalista com experiência e formação sólidas; também, pela solidez da presença de uma posição clínica, estruturante do próprio texto. Preciso fazer uma confissão pública que, até então, estava só no confessionário de laços que considerava não me excomungarem: concebo que para trabalhar na saúde mental se precisaria de uma pré-disposição psíquica, em que estaria em causa uma flexibilidade psíquica. Ou seja, é um campo nada fértil para a rigidez e o controle. Certa "natureza psíquica" que podemos ir formando, polindo, aperfeiçoando. Haveria, assim, um Real constitutivo - para não ser tão biológica, embora essa ciência tenha sido, também, fundamental à constituição da psicanálise. Um Real estrutural para se dispor a encontrar com um outro tão frágil, tão descontrolado, tão desamparado, tão sem dentes, tão sem perfumes, em 
condições ambientais de vida, na sua maioria, que fazem jus àqueles que ali transitam. Tal posição na obra de Teresa está, estruturalmente, no estilo da escrita.

Servidor Público. Bela palavra encontrada no campo semântico de Sofrimento psíquico à margem do SUS! A autora, originariamente, reposiciona aquela palavra, como tantas outras. Uma palavra reposicionada produz nova significação, ou, numa linguagem lacaniana: significantes que se deslocam compondo campos de significações. Servidor Público. Servir a dor do comum. Uma dor que constitui a nós todos. É preciso estabilidade (sic!). Servir à dor não seria, por acaso, uma posição máxima da clínica? Se a clínica é colocar-se, debruçar-se ao leito para examinar o doente, aqui é servir psiquicamente à existência do outro. Servir como uma disposição que alimenta todo o método clínico, extenuadamente, experiência tratada no primeiro capítulo da obra, por meio das elaborações e fundamentações de Manoel Tosta Berlinck, orientador da Tese de Doutorado da autora. Essa parece ser uma máxima que atravessa do início ao fim a obra que nos deleita.

No capítulo "Territórios da exclusão", juntamente com um amplo histórico acerca da constituição dos "excluídos", apresenta uma reflexão acerca do contexto onde essa clínica está inserida, tensionando os polos inclusão $<>$ exclusão, por meio do conceito freudiando de Unheimliche, do estranho familiar. Pois, se refere "um campo vasto e profícuo produtor de angústia, daquilo que no clínico é capaz de produzir afastamento, estranhamento e horror" (Endo, p. 65). O sujeito inserido seria, no entanto, aquele que conseguiu ser capturado pelo olhar inquietante do outro.

No capítulo seguinte, acompanhamos uma trajetória histórico-conceitual acerca da melancolia, fundamentalmente, a partir do estudo de Moacir Scliar, "O nascimento da melancolia". Tal trajetória, desde a Grécia Antiga com estudos de Hipócrates sobre os humores melancólicos, objetiva mostrar o quanto os estados melancólicos estão presentes no cotidiano das práticas do SUS. No entanto, para Endo, desses estados de autodepreciação e apequenamento de si, identificados com uma estética de abandono, pouco se fala e se estuda.

A partir daquele capítulo, acompanhamos a terra fértil em que a obra se extrai. Ou seja, casos clínicos — de Patrícia, Madalena, Marilene e Silvio, entre outros. A forma metodológica das exposições faz jus ao legado freudiano. No final do século XIX, Freud realizou uma subversão na concepção vigente de psíquico e na forma de tratamento e narrativa do pathos. Quando ele des-cobre e posiciona o inconsciente como alicerce do psiquismo, 


\section{RESENHAS BIBLIOGRÁFICAS}

introduz uma forma particular de tratar o psicopatológico, deslocando o olhar à escuta, o tratamento da doença para o do doente (Krankengeschichte), particularizando uma posição a quem é endereçado à linguagem desse pathos. Assim, quando Freud enuncia que suas histórias clínicas parecem mais histórias literárias do que pesquisas científicas, devido à natureza do objeto e não por seu livre arbítrio, ele apresenta sua produção não como resultado de uma pessoalidade, mas a transmissão de uma posição em relação a esse sujeito cuja psicopatologia não é descritiva, mas narrativa.

A autora de Sofrimento psíquico, que compõe um dos pensamentos mais originais nesse campo, serve à dor do outro, porém não ela não está sozinha. Outra máxima. Bem sabemos que, se nos lançarmos a algumas margens de nossa geografia psíquica a sós, podermos estar propensos a errâncias ou quedas, como à margem de um precipício. O corpo curva-se em demasia. Por isso, junto com a autora (lá) estão importantes autores (da literatura brasileira) no campo da saúde mental e da psicanálise: o pensamento do militante Paulo Amarante, o pensamento "abre alas" da psicanálise na saúde mental, de produção sempre oxigenada, de Ana Cristina Figueiredo; além das reflexões, no campo da psicopatologia fundamental, de Manoel Berlinck, cuja falta nos é irreparável. Destaco ainda, Freud, seu guia, além de outros psicanalistas contemporâneos, destacando as elaborações de Edson de Sousa. A autora serve à dor do outro, mas, sempre com seus pares e ímpares na academia, no serviço público, na clínica, na vida familiar e em outros laços.

A literatura é também um campo no qual se compõem as profundezas e as margens da escuta clínica. Em Sofrimento psíquico, há uma elevação do legado freudiano da literatura como um dos campos mais férteis da constituição da psicanálise. Essa interlocução está presente na forma de um fragmento clínico que remete a uma passagem literária, como na posição do paciente Pedro que endereça ao fragmento de Grande Sertão: Veredas: "Eu atravesso as coisas - no meio da travessia as vejo! — só estava era entretido na ideia dos lugares de saída e de chegada" (Endo, p. 80). Um personagem pode compor elementos ilustrativos de um sujeito o qual se escuta. Há muitas Macabeas (personagem da Hora da estrela, de Clarice Lispector) em nossas instituições, remete Teresa Endo no caso clínico de Madalena. A própria escrita da obra é literariamente clínica, com figuras de linguagem que reposicionam significantes.

Talvez a mulher loira, indicada no início destp.,a resenha, que tenta transformar, ludicamente, sua dor, e se absorve nos trechos de Sofrimento psíquico, sabe que é um livro também escrito para ela: um convite para se 
inclinar por onde as margens podem ser recompostas. Creio que é isso que também consagra essa obra como uma das obras-primas no campo da clínica no serviço público: aquece o gélido dos confinamentos e vastidões das geografias institucionais.

Citação/Citation: Oliveira, I. M. de. (2017, dezembro). Geografias psíquicas. Resenha do livro Sofrimento psíquico à margem do SUS: vastidão e confinamento da clínica. Revista Latinoamericana de Psicopatologia Fundamental, 20(4), 806-810. http://dx.doi.org/10.1590/ 1415-4714.2017v20n4p806-13

Editores do artigo/Editors: Profa. Dra. Sonia Leite

Recebido/Received: 27.9.2017 /9.27.2017 Aceito/Accepted: 20.10.2017 / 10.20.2017

Copyright: (C) 2009 Associação Universitária de Pesquisa em Psicopatologia Fundamental/ University Association for Research in Fundamental Psychopathology. Este é um artigo de livre acesso, que permite uso irrestrito, distribuição e reprodução em qualquer meio, desde que o autor e a fonte sejam citados / This is an open-access article, which permits unrestricted use, distribution, and reproduction in any medium, provided the original authors and sources are credited.

\section{Iza Maria de Oliveira}

Doutora em Psicologia Clínica pela Pontifícia Universidade Católica de São Paulo PUC-SP (São Paulo, SP, Br); Mestre em Estudos Literários/Literatura e Psicanálise pela Universidade Federal de Santa Maria - UFSM (Santa Maria, RS. Br); Psicanalista; Cronista.

Rua Sete de Setembro, 345/24 - Centro

98700-000 Ijuí, RS, Br

izamaria.abadi@gmail.com

This is an open-access article, which permits unrestricted use, distribution,

\section{BY-NC} and reproduction in any medium for non-commercial purposes provided the original authors and sources are credited. 